\title{
FORMAÇÃO INICIAL DE PROFESSORES DA EDUCAÇÃO BÁSICA EM LICENCIATURAS DE UNIVERSIDADES PÚBLICAS DO RIO GRANDE DO NORTE: ESTUDO DE CURRÍCULOS E SUAS MATRIZES CURRICULARES
}

\author{
FORMACIÓN INICIAL DE DOCENTES DEL EDUCACIÓN BÁSICA EN \\ LICENCIATURAS DE UNIVERSIDADES PÚBLICAS DE RIO GRANDE DO NORTE: \\ ESTUDIO DE CURRÍCULOS Y SUS MATRICES CURRICULARES
}

\author{
INITIAL FORMATION OF TEACHERS OF BASIC EDUCATION IN \\ UNDERGRADUATE DEGREES OF PUBLIC UNIVERSITIES OF RIO GRANDE DO \\ NORTE: STUDY OF CURRICULA AND THEIR CURRICULAR MATRICES
}

\author{
Emerson Augusto de MEDEIROS ${ }^{1}$
}

Ana Lúcia Oliveira AGUIAR ${ }^{2}$

RESUMO: O texto em tela tem como objetivo principal apresentar uma análise acerca da formação inicial de professores da Educação Básica em 58 cursos de licenciatura de três universidades públicas do Estado do Rio Grande do Norte, com ênfase para o estudo de currículos e de suas matrizes curriculares. Trata-se de uma pesquisa documental que se apoia na análise de documentos curriculares referentes à formação docente nas graduações. Concluímos que as licenciaturas analisadas necessitam aprofundar em seus currículos o estudo sistemático da Educação. Acreditamos que, por essa via, poderemos pensar em processos de formação inicial docente mais significativos a respeito do estudo da docência, principal eixo defendido pelas entidades educacionais e movimentos sociais na história para a formação de professores no Brasil, o qual é referência central nas novas Diretrizes Curriculares Nacionais para a formação inicial e continuada dos professores da Educação Básica.

PALAVRAS-CHAVE: Formação inicial de professores. Licenciaturas. Currículo. Matrizes curriculares.

RESUMEN: El objetivo principal del texto es presentar un análisis de la formación inicial de maestros de Educación Básica en 58 cursos de licenciatura de tres universidades públicas del estado de Rio Grande do Norte, con énfasis en el estudio de los currículos y sus matrices curriculares. Se trata de una investigación documental que se basa en el análisis de los documentos curriculares relativos a la formación docente en las graduaciones. Concluimos que las licenciaturas necesitan profundizar en su currículo el estudio sistemático de la educación. Creemos que de esta manera podremos pensar en la enseñanza inicial más

${ }^{1}$ Universidade Federal Rural do Semi-Árido (UFERSA), Mossoró - RN - Brasil. Professor Assistente do Departamento de Ciências Humanas. Doutorando em Educação pelo Programa de Pós-Graduação em Educação da Universidade Estadual do Ceará (UECE). Bolsista do Programa PRODOUTORAL/CAPES. ORCID: <http://orcid.org/0000-0003-3988-3915>. E-mail: emerson.medeiros@ufersa.edu.br.

${ }^{2}$ Universidade do Estado do Rio Grande do Norte (UERN), Mossoró - RN - Brasil. Professora Adjunta do Departamento de Educação e Docente do Programa de Pós-Graduação em Educação (POSEDUC/UERN). Doutora em Sociologia. Realizou Estágio Pós-Doutoral em Educação pela Universidade Federal do Ceará (UFC). ORCID: <http://orcid.org/0000-0003-3626-2427>. E-mail: aguiarpietro@gmail.com. 
significativa de los procesos de formación sobre el estudio de la docencia, el eje principal propugnado por las entidades educativas y los movimientos sociales en la historia para la formación de los docentes en Brasil, que es Referencia central en las nuevas directrices nacionales del currículo para la formación inicial y continuada de los docentes de Educación Básica.

PALABRAS CLAVE: Formación inicial de maestros. Licenciaturas. Currículo. Matrices curriculares.

ABSTRACT: The objective of this study is to present an analysis of the initial formation of teachers of Basic Education in 58 courses of Bachelor of three public universities of the state of Rio Grande do Norte, with emphasis on the study of curricula and their curricular matrices. It is a documentary research that is based on the analysis of curriculum documents pertaining to the teaching training in the graduations. We conclude that the studied degrees need to deepen in their curriculum the systematic study of education. We believe that, by this way, we will be able to think of more significant teaching initial training processes regarding the study of teaching, the main axis advocated by educational entities and social movements in history for the formation of teachers in Brazil, which is central reference in the new national curriculum guidelines for the initial and continuing training of teachers of basic education.

KEYWORDS: Initial teacher formation. Degree course. Curriculum. Curricular matrices.

\section{Introdução}

Em recente publicação, Gatti (2016) assinala que a formação inicial de professores da Educação Básica no Brasil não conseguiu se desmembrar de problemas históricos presentes nos processos formativos nas licenciaturas e nos cursos destinados a formar o professor para atuação no Magistério Básico. Segundo a autora, apesar dos avanços no âmbito normativo e do aumento nos últimos anos da produção científica sobre o tema, permanecem nos currículos das licenciaturas questões que colocam em xeque a natureza das propostas formativas, bem como, ainda, dos conhecimentos e dos conteúdos fundamentais à formação do professor.

Realizando, neste parágrafo, uma pequena digressão histórica dos problemas relacionados à formação inicial de professores da Educação Básica com base nas produções de Gatti et al (2016), Dias e Passos (2016) e Mascarenhas e Franco (2017), consideramos que desde o seu surgimento, nas antigas Escolas Normais, são verificáveis ambiguidades criadas nos cursos de formação inicial docente, seja no que confere ao/à perfil/identidade profissional desejada para o docente da Educação Básica no País, seja nas estruturas disciplinares e fragmentadas dos currículos dos cursos ou na dicotomia existente nas matrizes curriculares 
entre os conhecimentos específicos da matéria a ensinar e os conhecimentos considerados didático-pedagógicos.

Este estudo, seguindo essa compreensão, objetiva apresentar uma análise sobre a formação inicial de professores da Educação Básica em cursos de licenciatura de três universidades públicas do Estado do Rio Grande do Norte, quais sejam: Universidade Federal do Rio Grande do Norte - UFRN, Universidade Federal Rural do Semi-Árido - UFERSA e Universidade do Estado do Rio Grande do Norte - UERN ${ }^{3}$. A partir de uma pesquisa documental, foram estudados os currículos e as matrizes curriculares de 58 licenciaturas na modalidade presencial. Em pormenores, focalizamos para discussão e análise o quantitativo de horas e semestres letivos considerados para a formação inicial docente nos cursos, do mesmo modo, o tempo orientado à formação didático-pedagógica e os componentes curriculares ditos pedagógicos e seus conhecimentos e conteúdos.

Reforçamos que além desses aspectos preocupamo-nos em caracterizar, a partir da investigação, a distribuição dos cursos por instituição formativa, bem como as áreas de formação das licenciaturas predominantes nas universidades pesquisadas. A realidade encontrada favorece a abertura de reflexões acerca da formação inicial docente dos contextos analisados.

Como as Diretrizes Curriculares Nacionais para essas graduações são amplas, e a estruturação dos currículos fica a cargo de cada instituição formativa, procuramos obter, parcialmente, um panorama do que está sendo proposto como formação inicial docente nas três Instituições de Educação Superior públicas do Rio Grande do Norte.

Destacamos, a título de informação, que o estudo teve como atenção central os cursos de licenciatura para a formação inicial de professores para os anos finais do Ensino Fundamental e para o Ensino Médio. Por entendermos a necessidade de delimitação e análise acurada da realidade, tendenciamos nosso interesse para as graduações que abarcam a formação inicial docente para as etapas educativas anteriormente assinaladas.

Traçada esta introdução, organizamos as seções seguintes em quatro momentos. Inicialmente, abordaremos de maneira sucinta a formação inicial de professores para a Educação Básica no Brasil, igualmente, os conceitos de licenciatura e de currículo relacionando-os ao foco de interesse desta investigação. Em segundo instante, sistematizaremos os aspectos metodológicos concernentes à concretização da pesquisa. No terceiro momento, apresentaremos a análise pretendida no que confere à realidade encontrada

\footnotetext{
${ }^{3}$ Esclarecemos que as três instituições são as únicas universidades públicas no Estado do Rio Grande do Norte.
} 
nos currículos e nas matrizes curriculares estudadas. Em última seção, discorreremos as conclusões advindas dos contextos investigados.

Por último, desejamos que as considerações expressas neste ensaio de pesquisa alimentem o corpo temático da Revista Ibero-Americana de Estudos em Educação nesta edição. Para nós, investigadores em Educação, pesquisar sobre a formação inicial de professores da Educação Básica é um desafio, dada a multiplicidade de olhares referente ao tema na esfera acadêmica. No entanto, o desejo de somar com reflexões atinentes à discussão foi um condicionante na empreitada investigativa realizada.

\section{Formação Inicial de Professores da Educação Básica, Licenciaturas e Currículo}

Não é de hoje que a formação inicial de professores da Educação Básica tem alcançado espaços nos discursos e debates realizados nos seminários, conferências e em outras ações de extensão em todo o mundo, como também em pesquisas produzidas na área de Educação, em especial, na pós-graduação stricto sensu.

Ao construírem o "Estado da Arte" sobre a produção científica em formação de professores no Brasil, André et. al (1999) certificam que, no contexto das produções de teses e dissertações desenvolvidas nos Programas de Pós-Graduação em Educação brasileiros, a formação inicial docente para a Educação Básica emerge como o principal tema de atenção pelos investigadores educacionais.

Brzezinski (2009), tal qual André et al (1999), ao analisar a produção acadêmica no Grupo de Trabalho "Formação de Professores" da Associação Nacional de Pós-Graduação e Pesquisa em Educação - ANPED, constatou que as pesquisas sobre a formação docente em cursos de licenciatura se sobressaem no rol dos trabalhos produzidos. Com ênfase, estão os estudos sobre os currículos e as propostas formativas, a avaliação e a qualidade da formação docente, a relação teoria e prática nos processos de formação, as políticas públicas de formação inicial de professores, entre outros.

No entanto, independente do volume de produções nas últimas décadas que tem direcionado seu olhar para o tema, ainda aparecem inúmeras dúvidas que diretamente atestam a necessidade de aprofundamento de pesquisas na área de formação de professores no Brasil. Para Gatti et al (2016) dentre as questões básicas que movem diálogos e, por vezes, incômodos nos diferentes espaços de formação do professor da Educação Básica estão: o que são as licenciaturas? Que currículos são necessários para caracterizar o perfil/identidade 
profissional do professor? Que conhecimentos e conteúdos devem fazer parte da formação inicial do professor da Educação Básica?

Antes de nos debruçarmos em apresentar alguns entendimentos acerca de parte dos apontamentos anteriores, haja vista que o espaço que temos não permite aprofundarmos as questões, é pertinente informar que tais questões fazem parte, em termos práticos, das realidades e períodos históricos que marcaram a formação inicial docente no Brasil. Dias e Passos (2016), com arrimo em Saviani (2009), afirmam que desde o momento inicial da formação de professores nos Cursos das Escolas Normais no período de 1927, passando pelo desenvolvimento das Escolas de Formação de Professores nos Institutos de Educação na década de 1930 e criação dos primeiros cursos de licenciatura a partir de 1939 nas Faculdades de Filosofia, Ciências e Letras, chegando ao momento atual, há a indefinição por parte das instituições formadoras e da legislação educacional acerca do que é formar o professor para atuação na Educação Básica.

Retomando o primeiro questionamento alertado por Gatti et al (2016), esclarecemos que concebemos as licenciaturas como cursos de formação inicial docente para atuação na Educação Básica, os quais conferem ao sujeito em formação habilidades profissionais, por meio de estudos teóricos e práticos, pesquisas e ações extensivas visando a apropriação de conhecimentos específicos relacionados à docência em diferentes contextos, etapas, níveis e modalidades educacionais, bem como à gestão de processos educativos escolares e não escolares (DOURADO, 2015; HONÓRIO et al, 2017). A vivência em um curso de licenciatura, conforme Dourado (2015), permite a construção de conhecimentos que denotam o início da identidade do profissional em formação.

No Brasil, há uma diversificação de áreas de formação docente para atuação na Educação Básica. Do mesmo modo, são múltiplas as instituições públicas e privadas que têm se preocupado em formar o professor. Todo esse cenário, somando-se a outras questões e problemas históricos de cunho social e, particularmente, da área educacional, culminou, nas últimas décadas, em debates e manifestações de entidades educacionais e movimentos sociais que, unindo educadores do ensino básico e superior, reivindicaram o que seria o eixo básico da formação inicial de professores no País nos cursos de licenciatura. Ora caminhando em consenso, ora palmilhando em contradições, essas instâncias definiram a docência como o princípio central da identidade profissional de todos os profissionais da Educação. Nessa direção, os cursos de licenciatura devem ter como atenção primária em seus currículos tal encaminhamento. 
Para tanto, inúmeros documentos, mesmo sem uma unicidade e sendo produzidos de forma fragmentada, têm povoado o aparato legislativo orientador da formação inicial de professores para a Educação Básica no Brasil, vislumbrando concretizar o aspecto supracitado. Como exemplo, temos no ano de 2015 a Resolução $n^{\circ}$ 02, de 01 de julho de 2015, do Conselho Nacional de Educação que "Define as Diretrizes Curriculares Nacionais para a formação inicial em nível superior (cursos de licenciatura, cursos de formação pedagógica para graduados e cursos de segunda licenciatura) e para a formação continuada" dos professores da Educação Básica ${ }^{4}$ (BRASIL, 2015).

Dourado (2015) diz que as novas Diretrizes Curriculares Nacionais, Resolução CNE/CP $\mathrm{n}^{\circ}$ 02, de 01 de julho de 2015, propunham atender a demanda levantada na história da Educação pelas diversas entidades educacionais e movimentos sociais ${ }^{5}$ no que confere à construção de uma base comum nacional para a formação de professores da Educação Básica, a qual conceba e sustente a docência como eixo basilar da formação docente. Para o autor, tais diretrizes indicam marcos formativos relevantes para a formação inicial - em especial - e continuada dos professores da Educação Básica ao direcionar princípios amplamente discutidos pela comunidade educacional, principalmente, os referentes à docência.

No que toca ao entendimento da docência, o referido documento em seu art. 2, parágrafo $1^{\circ}$, diz que a compreende como uma prática profissional que requer conhecimentos de natureza diversa (BRASIL, 2015). Dessa forma, não podemos limitar a formação inicial de professores unicamente aos aspectos interligados ao âmbito do saber ensinar ou do domínio dos conhecimentos específicos da matéria a lecionar. Nessa questão, os currículos de formação docente ganham centralidade.

Por currículo concebemos, com apoio em Sacristán (2013), como sendo todas as ações que ocorrem no ambiente educacional, quer de modo intencional ou não. Contudo, no campo dos estudos curriculares há discussões que vêm classificando e conceituando diferentes concepções de currículo. Entre elas, se encontra a concepção que se reporta aos documentos curriculares oficiais, os quais são entendidos como discursos institucionalizados que servem, entre outras funções, para orientar os processos educativos em uma instituição formativa,

${ }^{4} \mathrm{O}$ documento utiliza o termo "dos profissionais do magistério da Educação Básica" ampliando o raio de formação e atuação dos profissionais que atuam nessa etapa da Educação no País, aspecto defendido pelas entidades e movimentos sociais que participaram da elaboração da proposta das diretrizes. Neste texto, delimitaremos a utilização do termo para a formação de professores, uma vez que nossa atenção recai para a formação inicial docente.

${ }^{5} \mathrm{O}$ autor ressalva as seguintes entidades educacionais e movimentos sociais: Associação Nacional de PósGraduação e Pesquisa em Educação - ANPED, Associação Nacional pela Formação dos Profissionais em Educação - ANFOPE, Fórum Nacional de Diretores de Faculdades/Centros/Departamentos de Educação ou Equivalentes das Universidades Públicas Brasileiras - FORUMDIR, entre outros. 
assumindo também uma dimensão curricular, ou seja, de currículo (SACRISTÁN, 2013). Na formação inicial de professores da Educação Básica, temos inúmeros documentos que, conjuntamente, apontam os parâmetros necessários para se formar o professor. Os Projetos Pedagógicos de Cursos, as matrizes curriculares, os programas de disciplinas das graduações são exemplos dessa afirmação.

Esses documentos oficializam as decisões validadas pelos diferentes órgãos e setores nas instituições formativas - Conselho Universitário, Núcleo Docente Estruturante, Conselho de Curso, entre outros -, referentes à formação docente e devem, via de regra, orientar as ações formativas nos cursos de licenciatura.

Lembramos que os currículos dos cursos de formação docente são os responsáveis, em parte, por agregar os conhecimentos e os conteúdos necessários à formação inicial do professor. Nessa linha de raciocínio, Dias e Passos (2016) sublinham a importância de currículos que contemplem conhecimentos e conteúdos que sirvam de indicativo para se alcançar uma formação inicial docente mais próxima de um projeto educacional comprometido com a transformação da sociedade. Os conhecimentos e os conteúdos que englobam as questões éticas, ambientais, estéticas, políticas, econômicas, pedagógicas, dos direitos humanos, de gênero, das novas tecnologias, da cultura, entre outras, não podem passar à margem dos processos de formação inicial de professores. Posto isso, reafirmamos a necessidade de investigar os documentos curriculares dos cursos de licenciatura, pois, o instituído nos currículos, de certa maneira, tem um papel decisivo no profissional formado. É nessa perspectiva que damos continuidade à explanação do estudo apresentado neste instante.

\section{Procedimentos Metodológicos da Pesquisa}

Considerando o objetivo principal da investigação que condiz com a análise da formação inicial de professores da Educação Básica, mais especificamente ao estudo de currículos e de matrizes curriculares de 58 cursos de licenciatura de três universidades públicas do Rio Grande do Norte, com atenção para o quantitativo de horas e semestres letivos considerados para a formação docente, o tempo orientado à formação didáticopedagógica e os componentes curriculares ditos pedagógicos e seus conhecimentos e conteúdos, realizamos os procedimentos metodológicos a seguir:

No primeiro momento, fizemos o levantamento nos sites das três universidades pontuadas na investigação dos cursos de licenciatura existentes, ressalvando as graduações que pleiteiam a formação docente para atuação nos anos finais do Ensino Fundamental e 
Ensino Médio. Com esse procedimento, foi possível perceber o quantitativo de licenciaturas regulares na totalidade das universidades pesquisadas, assim como a distribuição das graduações por instituição e áreas de formação e os espaços territoriais em que estão circunscritas - se estão localizadas nos campi centrais das instituições formadoras ou não.

Subsequente, buscamos os Projetos Pedagógicos dos Cursos e/ou documentos que elucidassem as propostas de formação docente, a saber: resoluções e minutas com as matrizes curriculares dos cursos e ementários dos componentes curriculares das graduações; e realizamos a leitura dos mesmos. Essa etapa permitiu que identificássemos o quantitativo de horas e semestres letivos orientados para a formação inicial docente nas graduações, o total de tempo para a formação didático-pedagógica dos licenciandos e os componentes curriculares ditos pedagógicos e seus conhecimentos e conteúdos.

No terceiro instante, produzimos a análise quantitativa dos documentos. Nesse período, sistematizamos os dados referentes aos currículos e suas matrizes curriculares em um quadro e em gráficos para posteriormente concretizarmos a análise qualitativa do material encontrado.

Por fim, no quarto momento, desenvolvemos a análise qualitativa dos dados. Nessa fase, interpretamos os documentos agrupados a partir da sistematização dos dados no quadro e nos gráficos, perspectivando os sentidos que os dados inferem ao objetivo deste estudo. Com base no exposto, acentuamos que esse foi o caminho metodológico vivenciado na pesquisa. Mesmo sabendo que os resultados representam pouco para refletirmos acerca da formação inicial docente no País, acreditamos que a investigação é de suma importância para concebermos parte da realidade nos cursos de licenciatura no Rio Grande do Norte, quiçá, não muito distante de outros contextos brasileiros.

\section{Formação Inicial de Professores da Educação Básica em Cursos de Licenciatura: os currículos e suas matrizes curriculares}

Para começo de análise, informamos que encontramos licenciaturas na modalidade presencial na totalidade das universidades públicas do Rio Grande do Norte. Em relação às áreas de formação, não atípico à informação anterior, observamos graduações em diversas áreas de conhecimento ${ }^{6}$. Ressalvamos que mesmo não sendo o foco principal do estudo apresentar considerações sobre a distribuição dos cursos por instituição e visualizarmos as

${ }^{6}$ As áreas de formação descritas na sequência seguem a tabela de áreas de conhecimento validada pelo E-mec, espaço que porta as informações dos cursos de graduação das Instituições Federais de Educação Superior do País. 
áreas de formação inicial docente predominantes nas licenciaturas, bem como, ainda, a localização das graduações nas instituições formativas, avaliamos importante fazê-las porque acreditamos que somente com a compreensão desses aspectos conceberemos de modo integrado os currículos e as matrizes curriculares estudadas, outrossim, a realidade investigada.

Conforme descrito, há no Rio Grande do Norte 58 licenciaturas regulares para a formação inicial de professores para os anos finais do Ensino Fundamental e Ensino Médio situadas nas três universidades públicas existentes. Na distribuição dos cursos por instituição, percebemos que a Universidade do Estado do Rio Grande do Norte - UERN é a instituição com o maior número de graduações - 29 licenciaturas -, seguida da Universidade Federal do Rio Grande do Norte - UFRN - 24 cursos - e da Universidade Federal Rural do Semi-Árido - UFERSA - 05 graduações.

Para explicar essa realidade temos que ponderar dois aspectos: o primeiro pauta-se na constatação de que na esfera pública as instituições estaduais de Educação Superior concentram atualmente, de acordo com Barretto (2015), a maior parte dos cursos de formação inicial de professores no País. O segundo aspecto relaciona-se à questão de que as universidades federais têm, na história, assumido os cursos de bacharelado como os principais campos de interesse para o ensino (MAUÉS; SOUZA, 2016). Na UERN, há 59 cursos regulares de graduação na modalidade presencial, divididos em 33 cursos de licenciatura e 26 bacharelados. A UFRN, em outra direção, agrega 102 graduações organizadas em 26 licenciaturas e 76 bacharelados. A UFERSA, no mesmo intento, possui 39 cursos superiores distribuídos em 33 bacharelados e 06 licenciaturas.

Ao pesarmos esse panorama, fica entendível os motivos que atestam o maior percentual de licenciaturas na Universidade do Estado do Rio Grande do Norte - UERN. Fora isso, temos que ponderar que, desde o seu momento inicial de construção - ano de 1968 -, tal instituição primou pela formação inicial docente com a criação dos cursos de Licenciatura em Pedagogia, Letras, História e Ciências Sociais. As outras duas instituições, independente de juntas possuírem o valor significativo de graduações para formar professores da Educação Básica, vêm enfatizando a oferta de cursos de bacharelados e a expansão dessa modalidade de graduação nas áreas tecnológicas e de Engenharias.

$\mathrm{Na}$ organização das licenciaturas por áreas de conhecimento, verificamos que os cursos na área de Ciências da Linguagem, Comunicação e Artes, com as Licenciaturas em Letras Português, Letras Espanhol, Letras Libras, Letras Inglês, Letras Francês, Artes Visuais, 
Dança, Música e Teatro, abraçam o maior percentual de graduações. Nessa área há 23 licenciaturas.

A área de Ciências Humanas e Sociais, por vez, é contemplada com o quantitativo de 16 graduações para as disciplinas de Filosofia, Ciências Sociais/Sociologia, Geografia, História e Ciências da Religião. Uma peculiaridade constatada na organização das licenciaturas por áreas de formação trata-se da Universidade Federal Rural do Semi-Árido UFERSA não ofertar nenhuma licenciatura para a formação de professores dos anos finais do Ensino Fundamental e Ensino Médio na área de Ciências Humanas e Sociais.

Em menor proporção aparecem os cursos na área de Ciências Exatas e Naturais. As três instituições formativas congregam 11 licenciaturas em Ciências Biológicas/Biologia, Computação e Informática, Física, Matemática e Química. Ressalvamos que na história da Educação Básica no Brasil é inegável a carência de docentes formados nessa área de formação. Para Barretto (2015), a falta de docentes para atuação nas disciplinas de Física, Matemática e Química, em especial, é um grande problema que afeta a qualidade da educação nas escolas públicas de Educação Básica brasileiras.

Outra peculiaridade encontrada na organização das licenciaturas por áreas de formação relaciona-se à existência de cursos interdisciplinares - 02 graduações - e na área de Ciências da Saúde - 06 licenciaturas. Sabemos que, no momento, não é incomum a predominância de licenciaturas interdisciplinares na Educação Superior no País. De acordo com Maués e Souza (2016), após o Decreto 6.096, de 24 de abril de 2007, que instituiu o Programa de Apoio a Planos de Reestruturação e Expansão das Universidades Federais - REUNI, houve um significativo aumento de cursos de graduação em todo o País. As licenciaturas se associaram à expansão, sobretudo, com cursos na modalidade a distância e de caráter interdisciplinar. As duas graduações interdisciplinares são em Letras, com habilitações em Letras Português e em Letras Libras, e em Educação do Campo, com as habilitações em Ciências Humanas e Sociais e em Ciências Naturais.

Sobre os cursos na área de Ciências da Saúde emergem as licenciaturas em Enfermagem e Educação Física. Nos convidou a atenção o fato da existência de licenciaturas em Enfermagem, aspecto não comum no Brasil, posto que os cursos de Enfermagem possuem uma forte tradição na modalidade de bacharelado.

O próximo aspecto referente à análise dos cursos de licenciatura assenta-se na localização das graduações nas instituições formativas. Ordenamos as informações levantadas no Gráfico 1: 
Gráfico 1: localização das licenciaturas por campi nas instituições formativas

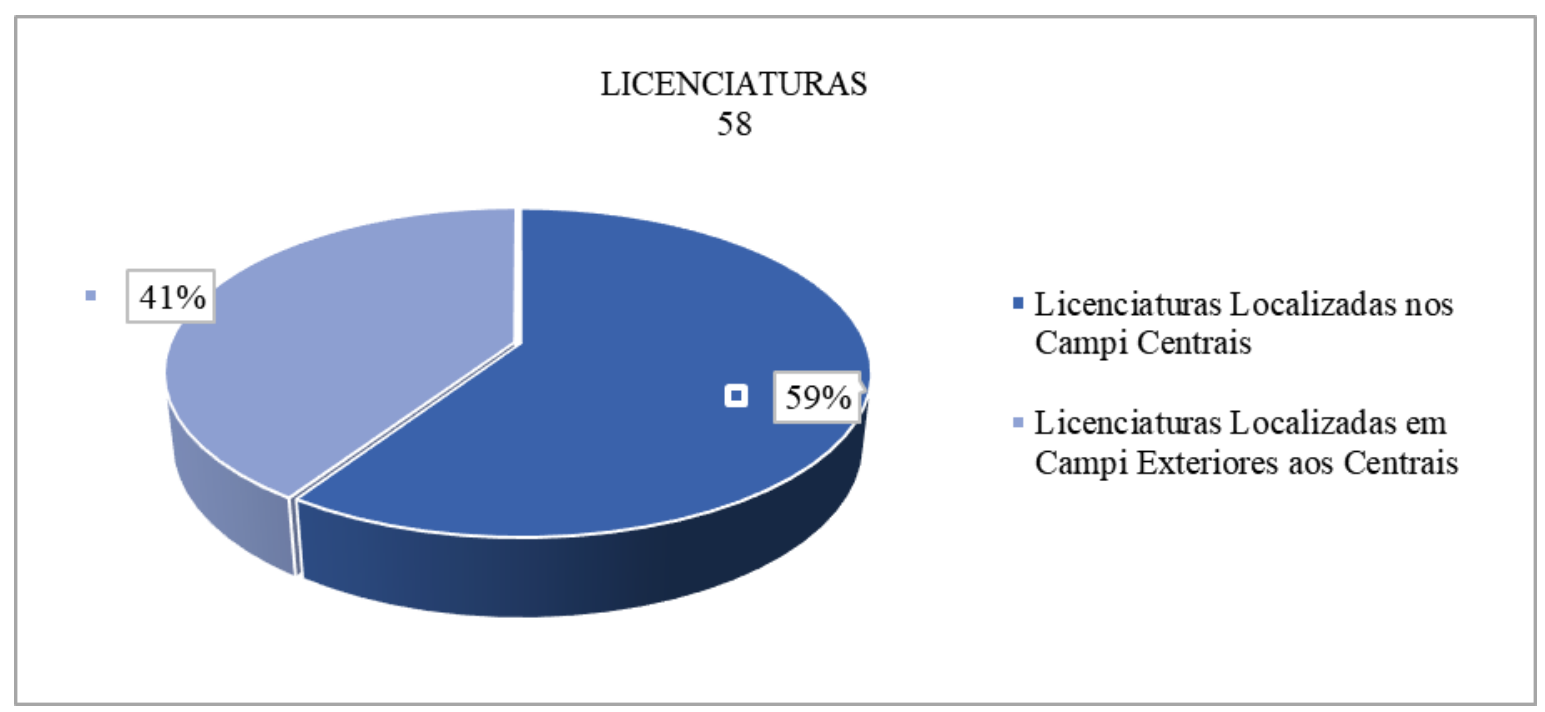

Fonte: Dados dos pesquisadores (2017)

Dos 58 cursos superiores para a formação inicial de professores da Educação Básica analisados, 34 - 59\% - se localizam nos campi centrais das instituições formativas. Desse valor, a Universidade Federal do Rio Grande do Norte - UFRN detém 19 licenciaturas em seu campus sede no Município de Natal - RN, a Universidade do Estado do Rio Grande do Norte - UERN porta 14 graduações e a Universidade Federal Rural do Semi-Árido - UFERSA dispõe de 01 curso, ambas nos Campi Centrais na cidade de Mossoró - RN.

As licenciaturas localizadas nos espaços exteriores aos campi sedes, no percentual de $41 \%$ - 24 graduações -, estão circunscritas em campi situados em 09 municípios do Rio Grande do Norte. A UERN, novamente, é a instituição que possui o maior número de cursos distribuídos nos espaços exteriores aos campi centrais. Ao todo, são 15 licenciaturas em campi nas cidades de Assú - 05 -, Pau dos Ferros - 07 -, Patu - 03 -, Caicó - 02 - e Natal $\mathrm{RN}$ - 01. A UFRN - 05 licenciaturas - e a UFERSA - 04 graduações - reúnem cursos nos Municípios de Angicos - 01 -, Caicó - 03 -, Caraúbas - 03 - e Currais Novos - RN - 02.

Cabe dizer que das 24 licenciaturas existentes nos campi não centrais somente três são da área de Ciências Exatas e Naturais - Matemática - 02 - e Computação e Informática - 01. As áreas de Ciências Humanas e Sociais e de Ciências da Linguagem, Comunicação e Artes contemplam a maior fração dos cursos nesses espaços.

Dada a expansão da Educação Superior nas últimas duas décadas - 1990 a 2010 -, com relevo em sua interiorização no Brasil, registramos também que os cursos de licenciatura localizados nas cidades em campi não centrais possuem menos tempo de funcionamento e criação. Como nota reflexiva dos achados, pensamos que a criação das licenciaturas nesses espaços acompanha, em parte, os desdobramentos da expansão do ensino superior nas cidades 
no interior do País. Neste sentido, como alertam Maués e Souza (2016), é fundamental ficarmos atentos à qualidade dos cursos situados nessas localidades, pois, problemas relacionados à infraestrutura - falta de bibliotecas e acervo bibliotecário, falta de laboratórios, condições inadequadas de funcionamento dos espaços físicos, entre outros -, ao número reduzido de professores formadores para atuar nas licenciaturas, à falta de interação entre o ensino, a pesquisa e a extensão, às (in)existentes políticas de permanência e assistência estudantis, vêm sendo identificados em pesquisas nesses espaços de formação docente.

Prosseguindo na análise acerca da formação inicial docente nas licenciaturas das três universidades públicas do Rio Grande do Norte, iniciaremos com as informações presentes nos currículos e nas matrizes curriculares. Em primeira referência, arrolamos sobre o total de horas destinado à formação inicial de professores nas graduações. Outra vez, listamos o que inventariamos no Gráfico a seguir:

Gráfico 2: horas destinadas à formação inicial docente nas licenciaturas TOTAL DE HORAS DOS CURSOS DE LICENCIATURA

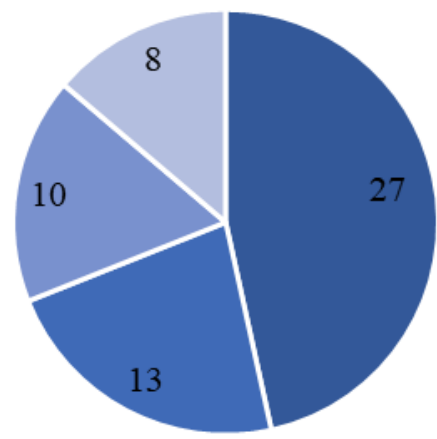

- Menos de 3.200

- Entre 3.200 e 3.399

$=$ Entre 3.400 e 3.600

- Acima de 3.600

Fonte: Dados dos pesquisadores (2017)

Conforme citamos em momento anterior do texto, tivemos no cenário da Educação Superior, no ano de 2015, a instituição das novas Diretrizes Curriculares Nacionais para a formação inicial e continuada dos professores da Educação Básica por intermédio da Resolução CNE/CP n 02 , de 01 de julho de 2015. Nesse documento se encontra prescrito, entre outras referências, o total de horas para os currículos das licenciaturas que visam formar docentes para atuação nos diferentes níveis, etapas e modalidades da Educação Básica brasileira.

Em passagem do texto da normativa (art. 13, parágrafo $1^{\circ}$ ) que aborda a estrutura e os currículos dos cursos de formação inicial docente diz-se que os cursos de licenciatura terão no mínimo 3.200 horas de efetivo trabalho acadêmico, em cursos com duração de, no mínimo, 08 
semestres letivos ou 04 anos (BRASIL, 2015). Visto o que prescreve o dispositivo legal a respeito do total de horas para a formação inicial docente nas licenciaturas, observamos que $53,5 \%$ dos currículos dos cursos atendem ao valor mínimo de tempo orientado para a formação inicial de professores nas graduações. Nesse percentual se encontram 13 licenciaturas com a carga horária entre 3.200 e 3.399 horas, 10 cursos com o valor entre 3.400 e 3.600 horas e 08 graduações com o número superior a 3.600 horas.

Concernente à ordenação dessas graduações nas instituições formativas que atendem ao estabelecido na normativa, a Universidade do Estado do Rio Grande do Norte - UERN possui 19 cursos, a Universidade Federal do Rio Grande do Norte - UFRN agrupa 08 licenciaturas e a Universidade Federal Rural do Semi-Árido - UFERSA concentra 01 graduação. Sobrelevamos que, na maioria das licenciaturas pertencentes às instituições UFERSA - 04 - e UFRN - 16 -, não é cumprido o previsto no documento legislativo. Para explicar essa conjuntura apoiamo-nos ao aspecto de que após a homologação das novas Diretrizes Curriculares Nacionais para a formação inicial e continuada de professores da Educação Básica foi dado o prazo de dois anos - finalizado em julho de 2017, com prorrogação de mais um ano pela Resolução CNE/CP n 1, de 09 de agosto de 2017 - para que as licenciaturas existentes no País e os cursos que estão em processo de elaboração revissem o pleiteado no documento.

Já as licenciaturas que estão com o valor de horas inferior ao estabelecido pela resolução vigente - no volume de 27 graduações -, sublinhamos que ao adentramos na leitura dos documentos curriculares - Projetos Pedagógicos de Cursos, minutas e resoluções percebemos que elas se amparam nas Diretrizes Curriculares Nacionais anteriores, via Resolução CNE/CP n ${ }^{\circ}$ 1, de 18 de fevereiro de 2002 e, mormente, na Resolução CNE/CP nº 2, de 19 de fevereiro de 2002, na qual se define no artigo $1^{\circ}$ o valor mínimo de 2.800 horas para os cursos superiores de formação inicial de professores. As 27 licenciaturas com o número menor de 3.200 horas confirmam o quantitativo entre 2.800 e 3.155 horas para a formação inicial docente.

Honório et al (2017), dissertando em revista sobre a proposta de formação docente nas novas Diretrizes Curriculares Nacionais para a formação inicial e continuada dos professores da Educação Básica, alertam que, em termos de organização curricular, o encaminhamento de 3.200 horas como quantitativo mínimo de tempo para a formação inicial docente nas licenciaturas é um desafio às instituições formativas, visto que reunir todas as orientações organização dos conhecimentos e conteúdos em três núcleos de formação, distribuição de tempo para a formação pedagógica e para os estágios curriculares supervisionados, incluindo 
ainda a gestão de processos educativos escolares e a docência em espaços não formais, entre outros -, em uma matriz curricular, muitas vezes com o número reduzido de professores formadores para atuação nos cursos, especialmente, para as graduações noturnas e para os cursos recém-criados advindos do REUNI, não é tarefa fácil.

Sobre o quantitativo de semestres letivos considerados para os processos formativos nas graduações, ordenamos o que identificamos no Gráfico consecutivo.

Gráfico 3: semestres letivos para a formação nas licenciaturas

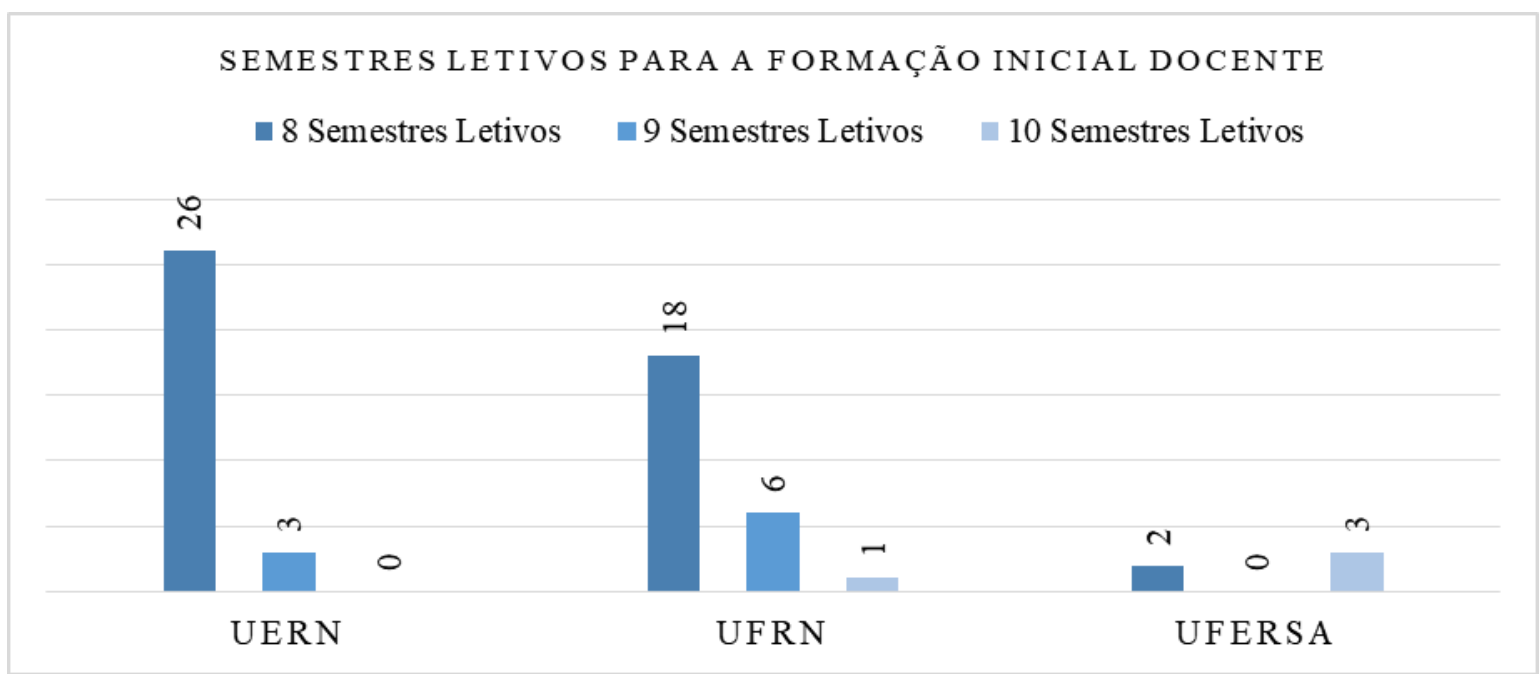

Fonte: Dados dos pesquisadores (2017)

Em parâmetros quantitativos, 43 licenciaturas perspectivam em seus currículos a formação inicial docente em 08 semestres letivos, o equivalente a 04 anos de estudos nas universidades. Os cursos das UERN e da UFRN em mais de $78 \%$ destinam esse período para formar professores nas graduações. A UFERSA, em outra linha, das 05 licenciaturas que oferta, somente duas propositam esse quantitativo de semestres letivos para os processos de formação inicial docente.

Acrescentamos que das 43 licenciaturas que conjecturam a formação inicial de professores em 08 semestres letivos, 31 funcionam no turno noturno. Quando direcionamonos para os cursos localizados nos campi exteriores aos centrais, constatamos que $85 \%$ das licenciaturas com 08 semestres letivos também priorizam o horário da noite para as atividades da formação inicial docente. Com relação aos cursos com o número de 09 ou 10 semestres letivos, no valor de 15 licenciaturas, tal característica não é acentuada. Desse total, não mais que 06 graduações desenvolvem suas atividades no turno noturno, sendo que 04 delas se localizam em campi não centrais.

No fito de aprofundarmos os considerandos sobre os semestres letivos pensados para as licenciaturas, condensamos alguns apontamentos a partir dos dados apresentados: em 
primeiro lugar, apontamos que o total de semestres letivos para a formação inicial docente nas licenciaturas não é delimitado, a nosso ver, ao número de horas para a formação nos cursos. $\mathrm{O}$ horário de funcionamento das graduações, nesta dimensão, tem forte influência. Os cursos noturnos - maioria das licenciaturas - são os que priorizam a formação de professores em 08 semestres letivos. Os cursos com 09 ou 10 semestres letivos funcionam, em peso, nos turnos matutino e vespertino, se encontrando cadastrados como diurnos.

As características mencionadas corroboram com o pensamento de Barretto (2015) e Gatti et. al (2016). Esses autores proferem que no plano da formação inicial de professores no Brasil os cursos de licenciaturas, de modo geral, seguem a perspectiva de oito semestres letivos - quatro anos - acompanhando o modelo histórico de formação docente nominado na literatura acadêmica educacional de $3+1^{7}$, no qual os conhecimentos e os conteúdos formativos se enquadram em matrizes curriculares disciplinares organizadas em três anos de estudos para os conhecimentos específicos da área de formação e um ano de estudos para os conhecimentos da área educacional. A prioridade dada à oferta de cursos noturnos facilita a perpetuação desse modelo, ao passo que atende à formação de docentes da Educação Básica com sujeitos oriundos de classes populares - trabalhadores assalariados e seus filhos, entre outros -, principal público de formação inicial docente das licenciaturas.

No contínuo da análise dos currículos e das matrizes curriculares, dialogamos, a partir deste instante, a respeito do total de horas para a formação didático-pedagógica nas graduações. Vejamos o que informa a próxima ilustração:

7 Barretto (2015) alude que ainda existem marcas nos cursos de licenciatura brasileiros do modelo $3+1$ de formação docente. Dentre elas se encontra a organização dos cursos em 04 anos e a separação nas matrizes curriculares dos conhecimentos do campo educacional e dos conhecimentos específicos da área de formação do professor. 
Gráfico 4: horas para a formação didático-pedagógica nas licenciaturas

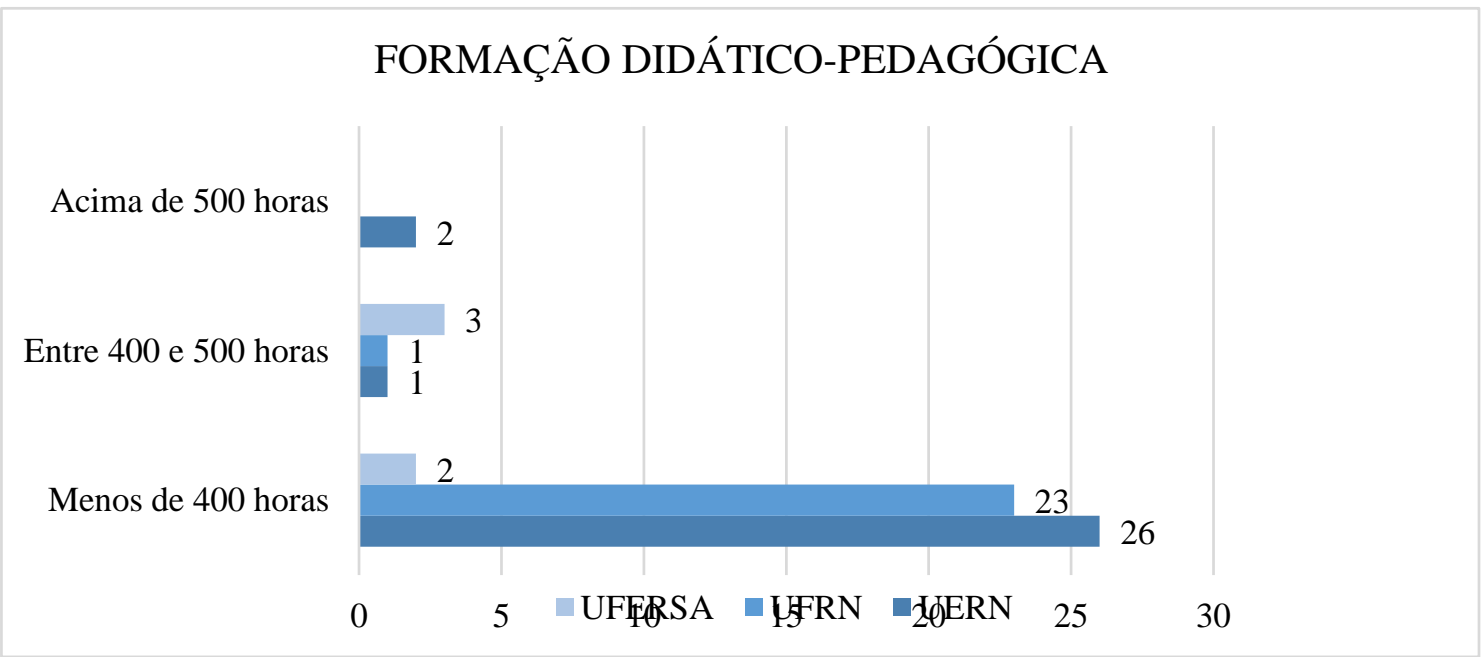

Fonte: Dados dos pesquisadores (2017)

Os currículos e as matrizes curriculares analisadas nos revelam que 51 licenciaturas demarcam menos de 400 horas para a formação didático-pedagógica dos licenciandos nas graduações. Evocamos que no art. 13, parágrafo $5^{\circ}$, das novas Diretrizes Curriculares Nacionais para a formação inicial e continuada dos professores da Educação Básica consta que para as licenciaturas, com exceção do curso de Pedagogia, o tempo dedicado às dimensões pedagógicas não deverá ser inferior à quinta parte da carga horária total dos cursos. Esse valor corresponde ao número de 640 horas para o estudo das dimensões didáticopedagógicas para as graduações com 3.200 horas (BRASIL, 2015). No raio do tempo mencionado, nenhuma licenciatura atinge ao propósito. Mesmo as 07 graduações que declaram nos currículos e nas matrizes curriculares mais de 400 horas para a formação pedagógica dos formandos, não identificamos registros que nos permitissem afirmar tal característica.

Destarte, nos preocupamos com o cenário delineado nos currículos e nas matrizes curriculares investigadas. Vimos, na quase totalidade das graduações, uma despreocupação ou como pronunciam Araújo, Rodrigues e Aragão (2017) um “(des)lugar” das questões referentes à Educação ${ }^{8}$ nos documentos curriculares analisados. A ênfase da formação inicial docente nas licenciaturas está no estudo dos conhecimentos das áreas específicas em que se almeja formar. Citamos, como exemplo, que nos cursos de Química se estuda química - da Química Básica à Química Geral, da Química Orgânica à Química Inorgânica -, e nos cursos de Ciências Sociais/Sociologia, se intenciona o estudo da Sociologia, da Antropologia, da

${ }^{8}$ Os autores fazem menção à Pedagogia e a Didática. Transpomos a expressão para a Educação. 
Ciência Política, entre outras; todavia, não validamos a interação dos conhecimentos dessas áreas com os conhecimentos das teorias do contexto da Educação.

A Didática é o único componente curricular da área de Educação atestado nas 58 licenciaturas. Entretanto, percebemos que nas matrizes curriculares tal disciplina emerge de maneira solta. Ela está presente, mas como um adendo aos currículos das graduações e não como um componente dos cursos para "tomar o ensino como prática social e, acima de tudo, levar os professores a construírem práticas pedagógicas transformadoras", nos termos de Araújo, Rodrigues e Aragão (2017, p. 217), citando Pimenta (2012, p. 29).

Adentrando no último aspecto analisado nas licenciaturas, o qual se refere justamente aos componentes curriculares ditos pedagógicos e seus conhecimentos e conteúdos, socializamos os dados fichados no Quadro 1.

Quadro 1: componentes curriculares, conhecimentos e conteúdos para a formação didáticopedagógica nas licenciaturas

\section{FORMAÇÃO DIDÁTICO-PEDAGÓGICA NAS LICENCIATURAS}

\begin{tabular}{|c|c|c|c|}
\hline $\begin{array}{l}\text { Dimensões da } \\
\text { Formação } \\
\text { Didático- } \\
\text { Pedagógica }\end{array}$ & $\begin{array}{l}\text { Componentes } \\
\text { Curriculares }\end{array}$ & Conhecimentos e Conteúdos & $\begin{array}{l}\text { Percentual } \\
\text { de } \\
\text { licenciaturas }\end{array}$ \\
\hline \multirow{4}{*}{$\begin{array}{l}\text { Dimensão } \\
\text { relativa aos } \\
\text { Fundamentos } \\
\text { Teóricos da } \\
\text { Educação }\end{array}$} & Filosofia da Educação & $\begin{array}{l}\text { O pensamento filosófico na formação de } \\
\text { professores; educação, trabalho e cultura, } \\
\text { subjetividade e ideologia; a filosofia na sala de aula. }\end{array}$ & $19,9 \%$ \\
\hline & História da Educação & $\begin{array}{l}\text { Educação Escolar em diferentes períodos históricos; } \\
\text { historiografia da Educação Básica; ideias e } \\
\text { tendências pedagógicas. }\end{array}$ & $10,5 \%$ \\
\hline & $\begin{array}{l}\text { Psicologia } \\
\text { Educação/da } \\
\text { Aprendizagem }\end{array}$ & $\begin{array}{l}\text { Teorias da Aprendizagem; Correntes da Psicologia } \\
\text { Contemporânea. }\end{array}$ & $85,1 \%$ \\
\hline & $\begin{array}{l}\text { Sociologia } \quad \text { da } \\
\text { Educação }\end{array}$ & $\begin{array}{l}\text { O ser humano e a sociedade; classes sociais e lutas } \\
\text { de classe; educação contra hegemônica. }\end{array}$ & $17,3 \%$ \\
\hline \multirow{2}{*}{$\begin{array}{l}\text { Dimensão } \\
\text { relativa aos } \\
\text { Sistemas } \\
\text { Educacionais }\end{array}$} & $\begin{array}{l}\text { Organização da } \\
\text { Educação Brasileira }\end{array}$ & 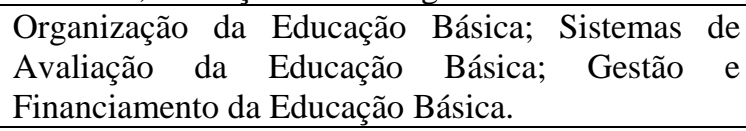 & 82,7 \\
\hline & Política Educacional & $\begin{array}{l}\text { Lei de Diretrizes e Bases da Educação Nacional, } \mathrm{n}^{\circ} \\
\text { 9.394/1996; Diretrizes Curriculares Nacionais para } \\
\text { o Ensino Fundamental e Ensino Médio; Plano } \\
\text { Nacional de Educação. }\end{array}$ & $10,5 \%$ \\
\hline \multirow{3}{*}{$\begin{array}{l}\text { Dimensão } \\
\text { relativa à } \\
\text { Didática e às } \\
\text { Metodologias/ } \\
\text { Práticas de } \\
\text { Ensino }\end{array}$} & Didática & $\begin{array}{l}\text { Didática - Natureza teórico-prática; Planejamento e } \\
\text { Educação; Métodos e Técnicas de Ensino; } \\
\text { Avaliação da Aprendizagem; Interdisciplinaridade. }\end{array}$ & $100 \%$ \\
\hline & $\begin{array}{l}\text { Metodologia/Instrume } \\
\text { ntação de Ensino }\end{array}$ & $\begin{array}{l}\text { Metodologias Específicas para os Ensinos das áreas } \\
\text { específicas de conhecimento. }\end{array}$ & $34,5 \%$ \\
\hline & Práticas Pedagógicas & $\begin{array}{l}\text { Práticas Pedagógicas em Espaços Escolares e Não } \\
\text { Escolares; Gestão Democrática; Projeto Político } \\
\text { Pedagógico. }\end{array}$ & $12,1 \%$ \\
\hline $\begin{array}{ll}\text { Dimensão } \\
\text { relativa às }\end{array}$ & Educação Especial & $\begin{array}{l}\text { Educação Inclusiva; Lei Brasileira de Inclusão, } \mathrm{n}^{\circ} \\
\text { 13.146/2015; Diversidade e Inclusão Social. }\end{array}$ & $22,5 \%$ \\
\hline
\end{tabular}




\begin{tabular}{|c|c|c|c|}
\hline $\begin{array}{l}\text { Modalidades } \\
\text { de Ensino da } \\
\text { Educação } \\
\text { Básica }\end{array}$ & $\begin{array}{lr}\text { Educação } & \text { em } \\
\text { Contextos } & \text { Não } \\
\text { Escolares } & \end{array}$ & $\begin{array}{l}\text { Educação Não Formal; Movimentos Sociais e } \\
\text { Educação; Educação Popular. }\end{array}$ & $10 \%$ \\
\hline \multirow[t]{2}{*}{$\begin{array}{l}\text { Outras } \\
\text { Dimensões }\end{array}$} & Educação Ambiental & $\begin{array}{l}\text { Meio Ambiente e Natureza; Educação Ambiental e } \\
\text { seus aspectos legais; Projetos Pedagógicos e a } \\
\text { Educação Ambiental. }\end{array}$ & $10 \%$ \\
\hline & $\begin{array}{l}\text { Tecnologias } \\
\text { Educação }\end{array}$ & $\begin{array}{l}\text { Tecnologias da Informação e da Comunicação; } \\
\text { Ferramentas Pedagógicas com o uso das tecnologias } \\
\text { na Educação. }\end{array}$ & $13,8 \%$ \\
\hline
\end{tabular}

Fonte: Dados dos pesquisadores (2017)

Os componentes curriculares com seus conhecimentos e conteúdos mencionados no Quadro 1 aparecem em pelo menos $10 \%$ dos currículos e matrizes curriculares analisadas. Nesse ensejo, esses referentes foram contemplados em, no mínimo, 05 currículos e matrizes curriculares.

Organizamos os achados em cinco dimensões construídas posteriormente à leitura dos documentos analisados ${ }^{9}$. Para nós, elas se fundem com conhecimentos e conteúdos da área de Educação, em especial, que são indispensáveis na formação didático-pedagógica do professor, são elas: Dimensão relativa aos Fundamentos Teóricos da Educação, Dimensão relativa aos Sistemas Educacionais, Dimensão relativa à Didática e às Metodologias/Práticas de Ensino, Dimensão relativa às Modalidades de Ensino da Educação Básica e Outras dimensões.

$\mathrm{Na}$ primeira dimensão, selecionamos os componentes curriculares das áreas de conhecimento que para Gatti et. al (2016) fundamentam e relacionam as questões sociais, políticas, econômicas, culturais, históricas e da psicologia com a Educação. Nesse conjunto, encontramos as disciplinas de Filosofia da Educação, Sociologia da Educação, Psicologia da Educação/da Aprendizagem e História da Educação. Notamos que as disciplinas pertencentes a esta dimensão emergem, quase sempre, no primeiro ou no segundo semestre letivo das matrizes curriculares e em ocasiões são unificadas em um único componente curricular. Os conhecimentos e os conteúdos das disciplinas incorporadas na dimensão em análise remetemse para discussões que relacionam uma área específica do conhecimento - Sociologia, História, Filosofia, entre outras - com a Educação.

Para a segunda dimensão, juntamos os componentes curriculares que se voltam para o estudo do sistema educacional brasileiro. Nesse conjunto, mencionamos duas disciplinas que

\footnotetext{
9 As dimensões construídas consideraram o estudo sobre a formação didático-pedagógica de professores desenvolvidos por Gatti et. al (2016). A formação didático-pedagógica é abordada nesse estudo como sendo a formação que qualifica o professor para o exercício da docência e para atuação em outros âmbitos da Educação gestão, coordenação, entre outras -, envolvendo estudos com diferentes conhecimentos: conhecimentos da Didática, da organização da educação - escolar e não escolar - e dos sistemas educacionais, das teorias e áreas que se aprofundam na investigação sobre a relação educação, sujeito e sociedade, entre outros.
} 
aparecem nos cursos: Organização da Educação Brasileira e Política Educacional. Seus conhecimentos e conteúdos primam pela legislação educacional e reúnem temas acerca da organização da Educação Básica no País.

A terceira dimensão é formada por componentes curriculares que se deslindam para o entorno da Didática, das Metodologias Específicas de Ensino para as áreas de formação e das Práticas Pedagógicas. É plausível registrar que em várias matrizes curriculares os conhecimentos e os conteúdos referentes a essa dimensão aparecem incluídos em disciplinas da área específica de formação. A impressão que tivemos é de que o componente curricular de Didática assume sozinho, ou em maior parte, as questões acerca dos processos de ensino e de aprendizagem nas licenciaturas. As 400 horas de prática como componente curricular orientadas nas novas Diretrizes Curriculares Nacionais para a formação inicial de professores da Educação Básica são distribuídas no rol das disciplinas específicas da área de formação. A rigor, apenas 07 licenciaturas elucidam como se desenvolverão tais práticas e o que são.

Quanto aos conhecimentos e aos conteúdos da dimensão em relevo, as temáticas relativas ao planejamento do ensino, à avaliação da aprendizagem, aos métodos e técnicas de ensino, à interdisciplinaridade, ao projeto político pedagógico das escolas, à gestão democrática, entre outros, preponderam nos documentos curriculares.

A quarta dimensão construída a partir dos achados da pesquisa copila as Modalidades Educativas da Educação Básica. As disciplinas de Educação Especial e Educação em Contextos Não Escolares se enquadram neste coletivo. Os conhecimentos e os conteúdos acerca da Educação Inclusiva, da Lei Brasileira de Inclusão - LBI, Lei nº 13.146/2015, da diversidade e inclusão social, da relação movimentos sociais e educação, entre outros, são as referências nos currículos e nas matrizes curriculares.

A última dimensão traz componentes curriculares que não se enquadram nas demais dimensões discutidas no texto, mas que se afirmam como relevantes para a formação didáticopedagógica do professor nas licenciaturas. As disciplinas de Educação Ambiental e Tecnologias e Educação se unem na presente dimensão. Os conhecimentos e os conteúdos que elas aglutinam tangem-se para as questões acerca da relação Meio Ambiente e Natureza, a Educação Ambiental e seus aspectos legais, as Tecnologias da Informação e da Comunicação na Educação, entre outros.

A síntese extraída do cenário descrito nos alerta para um grande problema na formação inicial docente. Segundo Araújo, Rodrigues e Aragão (2017) não há um lugar definido na formação de professores da Educação Básica para o estudo da Pedagogia e da Didática. Estendemos a tese argumentada pelos autores e defendemos, a partir do estudo dos 
currículos e de suas matrizes curriculares, que não há um espaço claro nos documentos curriculares dos cursos de licenciatura analisados, isto é, na formação inicial docente para o estudo da Educação.

Não identificamos componentes curriculares que se preocupassem com discussões acerca da profissão docente, do currículo, das inúmeras modalidades da Educação Básica Educação do Campo, Educação de Jovens, Adultos e Idosos, Educação a Distância, entre outras. Como consequência do cenário descrito, trazemos, em nota final, uma indagação para os leitores deste texto na intenção de que agucem suas perspectivas de pesquisas na área de Educação: é possível formar professores sem o estudo sistemático da área educacional?

Por fim, reiteramos nossa esperança e desejo de que nos próximos anos possamos efetivar nos cursos de licenciatura analisados currículos que estejam mais embasados no estudo sistemático da Educação. Acreditamos que, por essa via, poderemos pensar em processos de formação inicial docente mais significativos a respeito do estudo da docência, principal eixo defendido pelas entidades educacionais e movimentos sociais na história da educação para a formação de professores no Brasil, o qual é referência central nas novas Diretrizes Curriculares Nacionais para a formação inicial e continuada dos professores da Educação Básica.

\section{Considerações finais}

Com o apoio da análise expressa, chegamos ao final deste texto com alguns considerandos acerca da formação inicial de professores nos cursos analisados, porém, longe de assumirmos a posição de que a análise desenvolvida retrata um conhecimento fiel sobre o que existe nos currículos e nas matrizes curriculares investigadas. Pensamos como Fortunato (2017) quando esclarece que nenhum conhecimento pode ser tomado como dono absoluto da verdade, posto que, todo conhecimento está embebido de subjetividades e ilustra de modo parcial a realidade. Entretanto, nos esforçamos para elencar as principais conclusões que se desenharam a partir da pesquisa e de nossas reflexões:

a. Os cursos de licenciatura analisados apresentam a necessidade de aprofundar em seus currículos o estudo sistemático da Educação. Os componentes curriculares ditos pedagógicos aparecem nas matrizes curriculares sem interação com as demais disciplinas dos semestres letivos em que se situam, ou mesmo com as propostas curriculares de formação das graduações. 
b. O propositado para a formação didático-pedagógica nas licenciaturas é insuficiente e se contradiz com o previsto nas novas Diretrizes Curriculares Nacionais para a formação inicial e continuada dos professores da Educação Básica. As 400 horas pautadas na normativa para o estudo da prática como componente curricular, as quais visam a formação didático-pedagógica do licenciando, não emergem de maneira transparente nos documentos curriculares, ocasionando, talvez, a não relação entre teoria e prática nos processos de formação inicial docente.

c. Como não identificamos nos documentos curriculares uma interação entre a formação voltada ao estudo da Educação com o estudo da área específica que se propõe formar o professor, acreditamos que o estudo da docência, entendida como prática profissional que requer conhecimentos de natureza diversa, também se atrofia e não se apresenta como o eixo básico da formação nas licenciaturas.

Em linhas finais, esperamos que a análise produzida acerca da formação inicial de professores nas 58 licenciaturas das três universidades públicas do Rio Grande do Norte possa somar, de alguma maneira, no campo dos estudos da formação de professores no Brasil e também nas investigações dos pesquisadores que abraçam a formação docente como objeto contínuo de pesquisas.

\section{REFERÊNCIAS}

ANDRÉ, M. et al. Estado da Arte na Formação de Professores no Brasil. Educação \& Sociedade, Campinas, n. 68, p. 301-309, 1999.

ARAÚJO, O. H. A.; RODRIGUES, J. M. C.; ARAGÃO, W. H. O (des)lugar da pedagogia e da didática na formação dos professores. Revista on line de Política e Gestão Educacional, Araraquara, v. 21, n. 01, p. 215-226, 2017.

BARRETTO, E. S. de S. Políticas de Formação Docente para a Educação Básica no Brasil: embates contemporâneos. Revista Brasileira de Educação, Rio de Janeiro, v. 20, n. 62, p. 679-702, jul./set., 2015.

BRASIL. Resolução CNE/CEB, no 02 , de 01 de julho de 2015. Disponível em: <http://pronacampo.mec.gov.br/images/pdf/res_cne_cp_02_03072015.pdf>. Acesso em: 07 jan. 2017.

BRZEZINSKI, I. Pesquisa sobre formação de profissionais da educação no GT 8/Anped: travessia histórica. Revista Formação Docente, Belo Horizonte, v. 01, n. 01, p. 71-94, ago./dez., 2009. 
DIAS, A. M. I.; PASSOS, C. M. B. Passado e presente na formação de professores: por entre perspectivas históricas, legais e políticas. Revista Internacional de Formação de Professores (RIFP), Itapetininga, v. 1, n. 2, p. 85-108, 2016.

DOURADO, L. F. Diretrizes Curriculares Nacionais para a formação inicial e continuada dos profissionais do Magistério da Educação Básica: concepções e desafios. Educação \& Sociedade, Campinas, v. 36, n. 131, p. 299-324, abr./jun., 2015

FORTUNATO, I. Cientificamente Comprovado (?): reflexões sobre conhecimento científico. Holos, v. 2, p. 436-441, ago., 2017.

GATTI, A. B. Formação de professores: condições e problemas atuais. Revista Internacional de Formação de Professores (RIFP), Itapetininga, v. 1, n. 2, p. 161-171, 2016.

GATTI, A. B. et al. Referentes e critérios para a ação docente. Cadernos de Pesquisa, v. 46, p. 286-311, 2016.

HONÓRIO, M. G. et al. As novas diretrizes curriculares nacionais para formação inicial e continuada de professores da educação básica: entre recorrências e novas inquietações.

Revista Ibero-Americana de Estudos em Educação, Araraquara, v. 12, n. 3, p. 1736-1755, jul-set/2017.

MASCARENHAS, A. D. N.; FRANCO, M. A. S. De pedagogos a professores: balanço de uma década das diretrizes curriculares dos cursos de pedagogia no Brasil. Revista

Internacional de Formação de Professores (RIFP), Itapetininga, v. 2, n. 1, p. 41-55, 2017.

MAUÉS, O. C.; SOUZA, M. B. de. Precarização do trabalho docente da educação superior e os impactos na formação. Em Aberto, v. 29, n. 97, p. 73-86, set./dez. 2016.

SACRISTÁN, J. G. O que significa o currículo? In: SACRISTÁN, J. G. (Org.). Saberes e Incertezas sobre o currículo. Porto Alegre: Penso, 2013, p. 16-37.

\section{Como referenciar este artigo}

MEDEIROS, E. A.; AGUIAR, A. L. O. Formação inicial de professores da educação básica em licenciaturas de universidades públicas do Rio Grande do Norte: estudo de currículos e suas matrizes curriculares. Revista Ibero Americana de Estudos em Educação, Araraquara, v. 13 , n. 03 , p. 1028-1049, jul./set., 2018. E-ISSN:1982-5587. DOI: 10.21723/riaee.v13.n3.2018.10975

Submetido em: 29/01/2018

Aprovado em: 05/05/2018 